\title{
Frontiers in Nanoparticle \\ Research: Toward Greater Complexity of Structure and Function of Nanomaterials
}

\author{
By Nicholas A. Kotov* and Francesco Stellacci*
}

$T_{\text {he discovery of quantum size }}$ effects and methods of manufacturing of nanoparticles (NPs) can be described as two of the central scientific events in recent scientific as well as technological history. The inaugural Kavli Prize in Nanoscience (2008) was awarded jointly to Louis E. Brus, of Columbia University, US, and Sumio Iijima, of Meijo University in Japan, for their respective discoveries of colloidal semiconductor nanocrystals, also known as quantum dots, and carbon nanotubes." (http:// www.kavliprize.no/). This is an important recognition of the importance of the discovery of nanometer scale materials, which has created a whole new field of research. Since their discovery there has been a tremendous advancement in the fabrication techniques of diverse range of NPs. Syntheses of metallic, ${ }^{[1]}$ semiconductor, ${ }^{[2]}$ and magnetic ${ }^{[3]}$ NPs with different functionalities typically follow the same scheme as was suggested by Louis

[*] Prof. Nicholas A. Kotov Departments of Chemical Engineering, Materials Science and Engineering and Biomedical Engineering, University of Michigan Ann Arbor, MI 48109 (USA)

Email: kotov@umich.edu

Prof. Francesco Stellacci

Department of Materials Science and Engineering Massachusetts Institute of Technology Cambridge, MA, 02139 (USA) Email: frstella@mit.edu
Brus and Arnim Henglein at the beginning of the NP era. In most NP syntheses, an inorganic core $\left(\mathrm{Au}^{[4]}\right.$ or $\mathrm{Ag},{ }^{[5]}$ semiconductor $\mathrm{CdSe}^{[6]}$ or magnetic $\mathrm{Fe}_{2} \mathrm{O}_{3}{ }^{[7]}$ ) is coated with organic stabilizers (also known as ligands and capping agents) to provide colloidal stability in solution and protect the core atoms from unwanted reactions. $^{[8]}$ This general structure has resulted in unique versatility of nanoscale objects and, hence, potential applications. A quick search in Web of Science shows that in 2007 there were more than 14000 papers published on NPs, roughly 200 times more than ten years before. Many medium and large companies regularly use NPs for disparate applications, and tens of small companies are trying to commercialize novel applications of nanometer scale materials spanning a truly wide spectrum, ranging from fillers for tires to cosmetics, biotechnology, drug-delivery systems, energy and environment, and electronics.

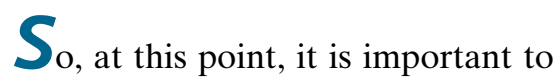
evaluate where we are and what are the next frontiers in this field. We believe that the papers in this special issue present an excellent snapshot of the field's development and also point to the key directions where we should expect the greatest progress in the future. One can analyze the current trends in the field with two perspectives: 1) practical properties driving the field forward; and 2) both intentional and serendipitous developments of experimental and theoretical techniques determining the key fundamental advances in the area. With respect to functionalities, the generally established areas such as optical materials, electronic devices, and biological applications will most likely continue to dominate for the next decade. The relative distribution of studies in NPs in these loosely defined areas of research are given in Figure 1a. Tremendous growth is observed in all of them (Fig. 1b). Not surprisingly, the growth in biological areas apparently surpasses that in composites and optical materials. We have attempted to cover all of these key areas in this issue, although arguably this can be done only cursorily within the available page limits.

In this issue, you will find the latest works $^{[9-11]}$ on electronic properties of NPs highlighting the new grounds and potential enabling technologies for optics and electronics. With respect to biology the reader is referred to the two reviews. ${ }^{[12,13]}$ We also have a few papers dedicated to some recent developments at the intersection of biology and NP 
research both in terms of nanocolloid-cell interactions ${ }^{[14]}$ and in terms of particles with biological functions ${ }^{[15]}$. Notably, some NPs have gained FDA approval in recent years, ${ }^{[16]}$ while many are in advanced clinical trials, a development aided by great efforts from science-funding agencies around the world. Giannelis presents an account of surprising new results in the area of NP composites taking a radically new approach to their preparation. ${ }^{[17]}$

$W_{\text {itt }}$ ith respect to new technical developments in the NP research, it is clear that the complexity of the NPs and, in particularly, their assemblies, is increasing steadily. We believe that this will be the general trend in the foreseeable future. This refers to the complexity of individual nanocolloids, which often combine two or more materials, and to the superstructures of their assemblies. In both respects NPs are proving to be extremely useful departing points for the creation of increasingly more complex objects and assemblies. We believe that NPs are among the most versatile building blocks for the creation of new tunable materials. ${ }^{[18]}$ The core-stabilizer structure of NPs affords treating them as individual building blocks creating complex 1-, ${ }^{[9,19-22]} 2-{ }^{[11,23-25]}$ and 3 -dimensional ${ }^{[26-28,23]}$ systems represented in this issue. Assembly of NPs into superstructures of greater complexity is a necessary step in the utilization of nanomaterials, be it in an ordered or in a less-ordered liquidlike $^{[17]}$ state. It is becoming apparent that NP superstructures greatly enhance the spectrum of properties in all functionalities mentioned above, from composites to biological materials, by allowing multiple interactions to be appended simultaneously onto the core of the particle. Analysis of the current trends also allows us to predict that the complexity of NP systems will increase not only with respect to spatial dimensions but also along the temporal coordinate, leading to dynamic nanometer-scale systems. $^{[29,30]}$

Wo believe that this issue presents many interesting points of departure for the study of many of the true challenges still present in the field of nanoparticles. It is becoming apparent that the use of nanoparticles in the industrial world soon will transition from simple additives with a single readily available property to complex multifunctional materials able to play a key enabling role in many fields and for a multitude of applications. For researchers, the most important and challenging part to be played in this transition is the understanding and engineering of the structure and the properties of NPs and of their suprastructures at the nanometer scale levels. Many elegant examples are, we are certain, still to follow.

[1] Y. G. Sun, Y. N. Xia, Science 2002, 298, 2176.

[2] C. B. Murray, D. J. Norris, M. G. Bawendi, J. Am. Chem. Soc. 1993, 115, 8706.

[3] S. H. Sun, Adv. Mater. 2006, 18, 393.

[4] M. Brust, M. Walker, D. Bethell, D. J. Schiffrin, R. J. Whyman, J. Chem. Soc, Chem. Commun. 1994, 801.

[5] J. C. Hulteen, D. A. Treichel, M. T. Smith, M. L. Duval, T. R. Jensen, R. P. Van Duyne, J. Phys. Chem. B 1999, 103, 3854.

[6] X. G. Peng, T. E. Wilson, A. P. Alivisatos, P. G. Schultz, Angew. Chem. Int. Ed. Engl. 1997, 36, 145.
[7] A. K. Boal, K. Das, M. Gray, V. M. Rotello, Chem. Mater. 2002, 14, 2628.

[8] A. C. Templeton, M. P. Wuelfing, R. W. Murray, Acc. Chem. Res. 2000, 33, 27.

[9] A. M. Funston, J. J. Jasieniak, P. Mulvaney, Adv. Mater. 2008, 20, 4274.

[10] G. Dukovic, M. G. Merkle, J. H. Nelson, S. H. Hughes, A. P. Alivisatos, Adv. Mater. 2008, 20, 4306.

[11] E. Elmalem, A. E. Saunders, R. Costi, A. Salant, U. Banin, Adv. Mater. 2008, 20, 4312.

[12] M. De, P. S. Ghosh, V. M. Rotello, $A d v$. Mater. 2008, 20, 4225.

[13] J. E. Ghadiali, M. M. Stevens, Adv. Mater. 2008, 20, 4359 .

[14] A. Muñoz_Javier, O. Kreft, M. Semmling, S. Kempter, A. G. Skirtach, O. Bruns, P. del Pino, M. F. Bedard, J. Rädler, J. Käs, C. Plank, G. B. Sukhorukov, W. J. Parak, $A d v$. Mater. 2008, 20, 4281.

[15] F. Manea, C. Bindoli, S. Fallarini, G. Lombardi, L. Polito, L. Lay, R. Bonomi, F. Mancin, P. Scrimin, Adv. Mater. 2008, 20, 4348.

[16] S. Y. Shaw, E. C. Westly, M. J. Pittet, A. Subramanian, S. L. Schreiber, R. Weissleder, Proc. Nat. Acad. Sci. 2007, 105, 7387.

[17] R. Rodriguez, R. Herrera, L. A. Archer, E. P. Giannelis, Adv. Mater. 2008, 20, 4353.

[18] A. P. Alivisatos, Science, 1996, 271, 933.

[19] G. A. DeVries, F. R. Talley, R. P. Carney, F. Stellacci, Adv. Mater. 2008, 20, 4243.

[20] P. Pramod, K. G. Thomas, Adv. Mater. 2008, 20, 4300 .

[21] V. Myroshnychenko, E. Carbó-Argibay, I. Pastoriza-Santos, J. Pérez-Juste, L. M. LizMarzán, F. J. García de Abajo, Adv. Mater. 2008, 20, 4288 .

[22] E. V. Shevchenko, M. I. Bodnarchuk, M. V. Kovalenko, D. V. Talapin, R. K. Smith, S. Aloni, W. Heiss, A. P. Alivisatos, $A d v$. Mater. 2008, 20, 4323.

[23] D. Fava, Z. Nie, M. A. Winnik, E. Kumacheva, Adv. Mater. 2008, 20, 4318.

[24] H. B. Xia, D. Y. Wang, Adv. Mater. 2008, 20, 4253.

[25] J-w. Seo, J-t. Jang, S-w. Park, C. Kim, B. Park, J. Cheon, Adv. Mater. 2008, 20, 4269.

[26] N. Gaponik, A. Wolf, R. Marx, V. Lesnyak, K. Schilling, A. Eychmüller, Adv. Mater. 2008, 20, 4257 .

[27] D. Ingert, M. P. Pileni, Adv. Mater. 2008, 20, 4336.

[28] V. Rastogi, S. Melle, O. G. Calderón, A. A. García, M. Marquez, O. D. Velev, $A d v$. Mater. 2008, 20, 4263.

[29] J. Lee, A. Govorov, N. A. Kotov, Angew. Chemie. Intl. Ed. 2005, 44, 7439.

[30] S. Westenhoff, N. A. Kotov, J. Am. Chem. Soc. 2002, 124, 2448 